\title{
Characteristics and outcome following transcatheter aortic valve replacement in patients with severe aortic stenosis with low flow
}

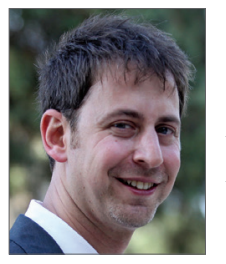

Yigal Abramowitz ${ }^{*}$, MD; Tarun Chakravarty ${ }^{1}$, MD; Philippe Pibarot², DVM, PhD; Yoshio Maeno ${ }^{1}$, MD, PhD; Hiroyuki Kawamori ${ }^{1}, \mathrm{MD}$, PhD; David Anderson ${ }^{1}$, BS; Geeteshwar Mangat ${ }^{1}$, MD; Mamoo Nakamura ${ }^{1}$, MD; Wen Cheng ${ }^{1}$, MD; Raj R. Makkar ${ }^{1}$, MD

1. The Heart Institute, Cedars-Sinai Medical Center, Los Angeles, CA, USA; 2. Québec Heart \& Lung Institute, Laval University Québec, Québec, Canada

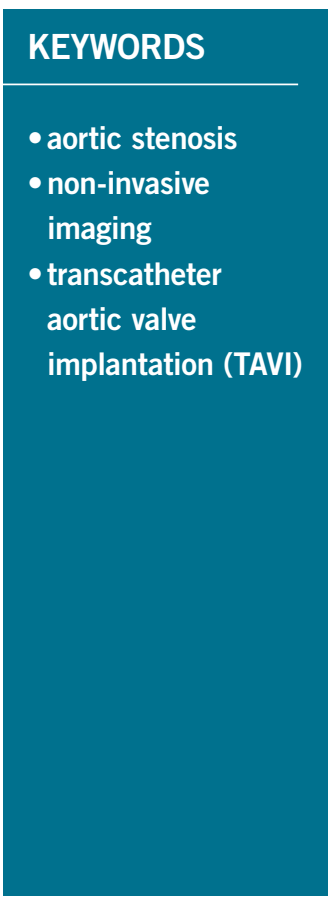

\begin{abstract}
Aims: Only a few studies have examined the respective impact of low flow (LF), low gradient (LG) and low ejection fraction (LEF) on outcomes following transcatheter aortic valve replacement (TAVR). The purpose of this study was to assess the impact of preprocedural stroke volume index, aortic valve gradient, left ventricular ejection fraction (LVEF) and different flow/gradient/LVEF patterns on the clinical outcomes of patients with severe aortic stenosis (AS) who undergo TAVR.
\end{abstract}

Methods and results: We analysed the clinical, echocardiographic, and outcome data collected in 770 patients with AS who underwent TAVR. Overall, 357 patients had normal flow (NF) AS and 413 had LF AS. Patients with NF had similar one-year mortality ( $12.0 \%$ vs. $15.0 \%, \mathrm{p}=0.23)$ compared with those in the LF group. Overall, patients with NF and/or HG had lower one-year mortality rates (11.7 to 13\%) compared to those with paradoxical LF-LG with NEF (19\%) and those with classical LF-LG with LEF (27.3\%). Low mean gradient was an independent predictor of all-cause mortality (hazard ratio: 1.14, per $10 \mathrm{mmHg}$ decrease, $\mathrm{p}=0.02$ ). Despite significant association in univariable analyses, $L F$ and LEF were not found to be predictors of outcomes in multivariable analyses.

Conclusions: Patients with HG and those with NF-LG have low one-year mortality rates following TAVR, whereas those with classical LF-LG and LEF and those with paradoxical LF-LG and NEF have high and intermediate risk of mortality, respectively. In contradiction to previous reports, LG but not LF or LEF is an independent predictor of late mortality in high-risk patients with severe AS undergoing TAVR.

\footnotetext{
*Corresponding author: Cedars-Sinai Heart Institute, 127 S. San Vicente Boulevard, AHSP, Suite A3600, Los Angeles, CA, 90048, USA.E-mail:yigalab@yahoo.com
} 


\section{Abbreviations}

AS

AVA aortic valve area

HF high flow

HG high gradient

LEF low ejection fraction

LF low flow

LG low gradient

LVEF left ventricular ejection fraction

LVOT left ventricular outflow tract

NEF normal ejection fraction

TAVR transcatheter aortic valve replacement

SVi stroke volume index

VTI velocity time integral

\section{Introduction}

Patients with severe aortic stenosis (AS) are often categorised based on left ventricular stroke volume index (SVi), aortic valve gradient and left ventricular ejection fraction (LVEF) ${ }^{1}$. They are further subdivided into subcategories such as low flow (LF) versus normal flow (NF), high gradient (HG) versus low gradient (LG) and normal ejection fraction (NEF) versus low ejection fraction (LEF). LF, LG and LEF were all shown to be predictors of mortality following surgical aortic valve replacement $(\mathrm{SAVR})^{1-4}$. On the basis of these three haemodynamic parameters, several patterns of flow/gradient/LVEF AS have been described: i) NF-HG (D1 Stage in the ACC/AHA guidelines); ii) NF-LG (no specific stage given in the guidelines); iii) LF-HG (D1 Stage); iv) paradoxical LF-LG with NEF (D3 Stage); and v) classical LF-LG with LEF (D2 Stage) $)^{5}$. A recent meta-analysis reported that, among patients with NEF, those with paradoxical LF-LG have worse outcomes compared to those with moderate AS and HG AS (D1) but their outcome was significantly improved by aortic valve replacement ${ }^{6}$. Furthermore, in this study, patients with NF-LG AS had similar survival to those with HG AS and their outcomes were also improved by surgical valve replacement.

Transcatheter aortic valve replacement (TAVR) has emerged as a treatment option for inoperable or high-risk surgical patients with severe $\mathrm{AS}^{7,8}$. Recent studies and meta-analyses have reported that the presence of low LVEF and low transvalvular aortic gradient prior to the procedure are associated with increased mortality following TAVR ${ }^{9-11}$. Nonetheless, only a few studies have examined the impact of LF or flow/gradient patterns on outcomes following TAVR ${ }^{12,13}$ and assessed the impact of the different flow/gradient categories on post-procedural outcomes. These studies represent the early experience with TAVR with significantly increased short-term mortality compared to recent years.

The objectives of the present study were to characterise patients with severe AS and LF who undergo TAVR and to assess the impact of preprocedural SVi, aortic valve gradient and LVEF on the clinical outcomes following this procedure.

\section{Methods}

We retrospectively examined the clinical and Doppler echocardiographic data prospectively collected in 825 consecutive patients who underwent TAVR between 2012 and 2014 at our institution. We excluded patients who had TAVR for indications other than severe AS or who had incomplete preprocedural Doppler echocardiographic data. Finally, 770 patients $(93.3 \%)$ were included in the study. The study was approved by the institutional review board (IRB) and informed consent was obtained from all subjects.

All patients had congestive heart failure with New York Heart Association (NYHA) Class II-IV symptoms. Aortic valve disease was assessed with transthoracic echocardiography performed by experienced echocardiographers. Evaluation of AS severity was performed based on peak velocity, mean gradient and calculation of the aortic valve area (AVA) using the continuity equation as recommended by current guidelines ${ }^{5}$. All patients had an indexed AVA (AVA/body surface area) of $<0.6 \mathrm{~cm}^{2} / \mathrm{m}^{2}$. Patients were considered to have $\mathrm{HG}$ severe AS if the mean transvalvular gradient was $\geq 40 \mathrm{mmHg}$ and LG if it was $<40 \mathrm{mmHg}$. Patients were also differentiated based on SVi (stroke volume/body surface area) into $\mathrm{LF}<35 \mathrm{ml} / \mathrm{m}^{2}$ and $\mathrm{NF} \geq 35 \mathrm{ml} / \mathrm{m}^{2}$. Stroke volume was calculated using the following formula: left ventricular outflow tract (LVOT) area $\times$ LVOT velocity time integral $(\mathrm{VTI})=\pi(\text { LVOT diameter } / 2)^{2} \times$ LVOT VTI. Patients with LF-LG AS were further divided by their LVEF into LEF (LVEF $<50 \%$ ) and NEF (LVEF $\geq 50 \%$ ) (Figure 1).

Patients were also evaluated by an ECG-gated, multislice CT angiography study with a SOMATOM ${ }^{\circledR}$ Sensation Cardiac 64 scanner or a SOMATOM ${ }^{\circledR}$ Definition Flash CT scanner (Siemens

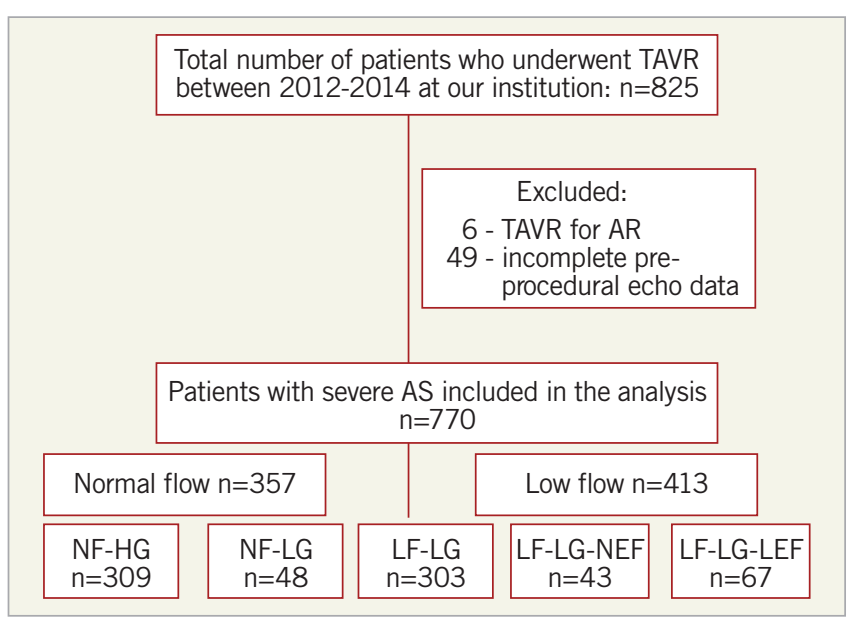

Figure 1. Flow chart for inclusion in the study. Patients were differentiated based on SVi (stroke volume/body surface area) into $L F<35 \mathrm{ml} / \mathrm{m}^{2}$ and $\mathrm{NF} \geq 35 \mathrm{ml} / \mathrm{m}^{2}$. Patients were considered to have $H G$ severe AS if the mean transvalvular gradient was $\geq 40 \mathrm{mmHg}$ and $L G$ if it was $<40 \mathrm{mmHg}$. $L E F$ was defined as $L V E F<50 \%$ and $N E F$ as $L V E F \geq 50 \%$. AS: aortic stenosis; $L F-H G$ : low flow and high gradient; $L F-L G-L E F$ : low flow, low gradient, and low ejection fraction; $L F-L G-N E F$ : low flow, low gradient, and normal ejection fraction; NF-HG: normal flow and high gradient; NF-LG: normal flow and low gradient 
Medical Solutions USA, Inc., Malvern, PA, USA). Aortic valve calcium was quantified by a standard Agatston methodology for all available non-contrast $\mathrm{CT}$ scans ${ }^{14}$.

All patients were considered high risk for valve surgery by our institutional Heart Team. Prosthetic valve size selection was based on CT or immediate preprocedural three-dimensional transoesophageal echocardiography. The vascular access approach was chosen on the basis of the individual patient's risk profile. Baseline clinical, echocardiographic and procedural details for TAVR were recorded for all patients including one-month clinical and echocardiographic assessments during a follow-up visit. TAVR endpoints, device success and adverse events were recorded using the Valve Academic Research Consortium (VARC)-2 definitions ${ }^{15}$. The primary endpoint of this study was all-cause mortality. Secondary endpoints were cardiovascular mortality, 30-day mortality and complication rates.

\section{STATISTICAL ANALYSIS}

Continuous variables were tested for distribution normality with the Shapiro-Wilk test and expressed as mean \pm SD or median and interquartile range. Because the Society of Thoracic Surgeons score was not normally distributed, a natural log transformation was used for this variable. Differences between groups were assessed using analysis of variance with subsequent Tukey HSD pairwise comparisons, two-sided Student's t-test or Wilcoxon rank-sum test, as appropriate. Categorical variables are expressed as number (percentage) and were compared using the Pearson $\chi^{2}$ test or the Fisher's exact test, as appropriate. Kaplan-Meier survival plot significance was estimated using the log-rank test. The effect of the clinical and Doppler echocardiographic variables on survival was assessed with Cox proportional hazards regression models for cumulative all-cause and cardiovascular mortality. Clinically relevant variables with a $p$-value $\leq 0.1$ on individual analysis were included in the multivariable models. All of the analyses were considered significant at a two-tailed p-value of less than 0.05. The SPSS statistical package, Version 20.0, was used to perform all statistical evaluation (IBM Corp., Armonk, NY, USA).

\section{Results}

\section{BASELINE AND PROCEDURAL CHARACTERISTICS BASELINE AND PROCEDURAL CHARACTERISTICS ACCORDING TO FLOW STATUS}

Overall, 357 (46.4\%) patients had NF AS and 413 (53.6\%) had LF AS. The baseline clinical patient characteristics and pre-TAVR imaging details of the study population are shown in Table 1.

Table 1. Baseline patient characteristics in patients with low vs. normal flow.

\begin{tabular}{|c|c|c|c|c|}
\hline & All patients $(n=770)$ & Low flow $(n=413)$ & Normal flow (n=357) & $p$-value \\
\hline Age, yrs & $82.0 \pm 8.7$ & $81.9 \pm 8.2$ & $82.2 \pm 9.3$ & 0.62 \\
\hline Male & $468(60.8)$ & $289(70.0)$ & $179(50.1)$ & $<0.001$ \\
\hline BMI & $26.8 \pm 5.7$ & $27.3 \pm 6.0$ & $26.1 \pm 5.4$ & 0.01 \\
\hline Hypertension & $702(91.2)$ & $378(91.5)$ & $324(90.8)$ & 0.71 \\
\hline Diabetes mellitus & 249 (32.3) & 154 (37.3) & $95(26.6)$ & 0.02 \\
\hline CAD & 499 (64.8) & $296(71.7)$ & 203 (56.9) & $<0.001$ \\
\hline Previous CABG & $199(25.8)$ & $130(31.5)$ & 69 (19.3) & $<0.001$ \\
\hline Previous MI & $127(16.5)$ & $86(20.8)$ & $41(11.5)$ & $<0.001$ \\
\hline PAD & $275(35.7)$ & $145(35.1)$ & $130(36.4)$ & 0.71 \\
\hline Previous stroke/TIA & $161(20.9)$ & $96(23.2)$ & $65(18.2)$ & 0.09 \\
\hline Chronic lung disease & $291(37.8)$ & $155(37.5)$ & $136(38.1)$ & 0.87 \\
\hline Chronic renal failure* & $134(17.4)$ & $61(14.8)$ & $73(20.4)$ & 0.04 \\
\hline Previous pacemaker & $164(21.3)$ & $114(27.6)$ & $50(14.0)$ & $<0.001$ \\
\hline Permanent atrial fibrillation/flutter & 254 (33.0) & $158(38.3)$ & $96(26.9)$ & 0.001 \\
\hline STS score, \% & $6.7(4.8-9.9)$ & $7.0(4.9-10)$ & $6.3(4.6-9.7)$ & 0.08 \\
\hline LVEF, \% & $57.0 \pm 15$ & $51.8 \pm 15.9$ & $62.9 \pm 10.8$ & $<0.001$ \\
\hline AVA, $\mathrm{cm}^{2}$ & $0.63 \pm 0.16$ & $0.58 \pm 0.16$ & $0.70 \pm 0.14$ & $<0.001$ \\
\hline AV mean gradient, $\mathrm{mmHg}$ & $45.5 \pm 13$ & $42.6 \pm 13.4$ & $48.8 \pm 12.7$ & $<0.001$ \\
\hline AV maximal gradient, $\mathrm{mmHg}$ & $76.4 \pm 21$ & $71.8 \pm 21.5$ & $81.6 \pm 19.6$ & $<0.001$ \\
\hline Stroke volume index, $\mathrm{ml} / \mathrm{m}^{2}$ & $34.6 \pm 10$ & $27.3 \pm 5.5$ & $43.0 \pm 7.1$ & $<0.001$ \\
\hline Moderate-severe AR & $77(10.0)$ & $38(9.2)$ & $39(11.0)$ & 0.43 \\
\hline Moderate-severe MR & $164(21.3)$ & $116(28.1)$ & $48(13.4)$ & $<0.001$ \\
\hline CT mean annulus diameter, $\mathrm{mm}$ & $24.3 \pm 2.7$ & $24.8 \pm 2.6$ & $23.7 \pm 2.6$ & $<0.001$ \\
\hline CT mean annulus area, $\mathrm{mm}^{2}$ & $466 \pm 98$ & $489 \pm 94$ & $439 \pm 95$ & $<0.001$ \\
\hline CT mean AV Agatston calcification score & $3,162(2,003-4,838)$ & $3,180(1,972-5,015)$ & $3,154(2,042-4,682)$ & 0.90 \\
\hline
\end{tabular}


Compared to the NF group, patients in the LF group were predominantly male, had a higher body mass index, and a higher prevalence of diabetes mellitus, coronary artery disease and permanent atrial fibrillation/flutter. The LF group had significantly lower baseline aortic valve area, and lower aortic valve mean/peak echo gradients $\left(0.58 \mathrm{~cm}^{2}\right.$ and $42.6 / 78.4 \mathrm{mmHg}$ vs. $0.70 \mathrm{~cm}^{2}$ and 48.8/81.6 mmHg, respectively; $\mathrm{p}<0.001$ for all). They also had higher rates of moderate-severe mitral regurgitation $(28.1 \%$ vs. $13.4 \%$, respectively, $\mathrm{p}<0.001)$.

Overall, the transfemoral approach was used in $86.4 \%$ of the cases, transapical approach in 5.3\%, transaortic approach in $7.0 \%$ and subclavian approach in $1.0 \%$. All patients had either Edwards SAPIEN/SAPIEN XT/SAPIEN 3 (Edwards Lifesciences, Irvine, CA, USA) or Medtronic CoreValve ${ }^{\circledR}$ (Medtronic, Minneapolis, MN, USA) implantation. Device success rate was $95.4 \%$ (394 of 413) for patients with LF compared with $95.2 \%$ (340 of 357) for patients with NF $(p=0.92)$. There were similar rates of post-procedural paravalvular regurgitation in both groups. Thirty-day complications are elaborated in Table 2. All complication rates were similar between groups.

Patient distribution is shown in Figure 2A. The percentage of males was significantly higher in all three LF subgroups compared to the NF-HG group. Patients with LF-LG-LEF had a significantly higher prevalence of diabetes mellitus, coronary artery disease, and atrial fibrillation compared to patients with NF-HG. Patients with LF-LG had significantly lower aortic valve calcification scores compared to patients with NF-HG and LF-HG.

\section{IMPACT OF FLOW, LVEF, AND GRADIENT ON 30-DAY AND} ONE-YEAR MORTALITY

Overall, there were 25 deaths at 30 days (3.2\%) (Figure 2B). Patients with NF had similar 30-day mortality compared with those in the LF group (10 of 357 [2.8\%] vs. 15 of 413 [3.6\%], respectively, $\mathrm{p}=0.52$ ). Among patients with LF-LG, 30-day mortality was not statistically different $(\mathrm{p}=0.56)$ between those with NEF (4.7\%) and those with LEF (7.5\%). One-year mortality
Table 2. Clinical outcome.

\begin{tabular}{|c|c|c|c|}
\hline & $\begin{array}{l}\text { Low flow } \\
(n=413)\end{array}$ & $\begin{array}{c}\text { Normal flow } \\
(n=357)\end{array}$ & $p$-value \\
\hline \multicolumn{4}{|l|}{30 days } \\
\hline Mortality & $15(3.6)$ & $10(2.8)$ & 0.52 \\
\hline CVA/TIA & $8(1.9)$ & $9(2.5)$ & 0.58 \\
\hline Myocardial infarction & $3(0.7)$ & $1(0.3)$ & 0.63 \\
\hline Respiratory failure & $15(3.6)$ & $8(2.2)$ & 0.26 \\
\hline Cardiogenic shock & $9(2.2)$ & $5(1.4)$ & 0.42 \\
\hline Cardiac tamponade & $2(0.5)$ & $2(0.6)$ & 1 \\
\hline Major bleeding & $14(3.4)$ & $18(5.0)$ & 0.25 \\
\hline Major vascular complications & $8(1.9)$ & $15(4.2)$ & 0.07 \\
\hline Minor vascular complications & $31(7.5)$ & $34(9.5)$ & 0.32 \\
\hline $\begin{array}{l}\text { New permanent pacemaker } \\
\text { implantation }\end{array}$ & $37(12.2)$ & 37 (11.9) & 0.92 \\
\hline Acute kidney injury stage 3 & $7(1.7)$ & $4(1.1)$ & 0.56 \\
\hline \multicolumn{4}{|l|}{1 year } \\
\hline Mortality & $61(15.0)$ & $42(12.0)$ & 0.23 \\
\hline
\end{tabular}

follow-up data were available for $759 / 770$ patients (98.6\%). Overall, there were 103 deaths at one year (13.6\%) (Figure 2C). Patients with NF had similar one-year mortality compared with those in the LF group (42 of 351 [12.0\%] vs. 61 of 408 [15.0\%], respectively, $\mathrm{p}=0.23$ ). Patients with $\mathrm{LF}-\mathrm{LG}$ had higher oneyear mortality $(24.1 \%)$ compared to the other groups $(p=0.001)$. Among patients with LF-LG, one-year mortality was not statistically different $(\mathrm{p}=0.33)$ between those with NEF $(19.0 \%)$ and those with LEF (27.3\%).

\section{IMPACT OF FLOW, LVEF, AND GRADIENT ON CUMULATIVE} MORTALITY

Overall, there were 209 deaths during a mean follow-up of $21.4 \pm 11.2$ months and 85 were of cardiovascular cause. Patients
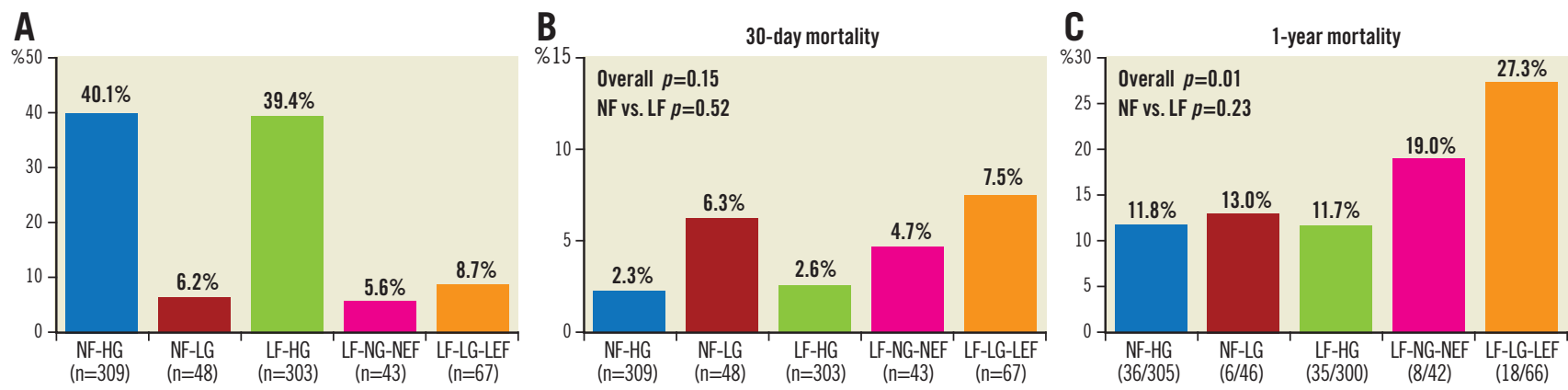

Figure 2. Patient distribution and mortality following TAVR according to flow, gradient, and ejection fraction status. A) Patient distribution according to flow ( $\left.N F \geq 35 \mathrm{ml} / \mathrm{m}^{2} ; \mathrm{LF}<35 \mathrm{ml} / \mathrm{m}^{2}\right)$, a ortic valve gradient ( $H G \geq 40 \mathrm{mmHg} ; \mathrm{LG}<40 \mathrm{mmHg}$ ) and left ventricular ejection fraction (NEF $\geq 50 \%$; LEF $<50 \%$ ). B) Incidence of 30-day mortality according to flow, gradient, and ejection fraction status. C) Incidence of one-year mortality according to flow, gradient, and ejection fraction status. $L F-H G$ : low flow and high gradient; $L F-L G-L E F$ : low flow, low gradient, and low ejection fraction; $L F-L G-N E F$ : low flow, low gradient, and normal ejection fraction; NF-HG: normal flow and high gradient; $N F-L G$ : normal flow and low gradient 
with LF had increased all-cause mortality (hazard ratio [HR]: 1.42, 95\% confidence interval $[\mathrm{CI}]: 1.07-1.87 ; \mathrm{p}=0.01)$ and cardiovascular mortality (HR: 1.85, 95\% CI: 1.18-2.90; $\mathrm{p}=0.01$ ) compared with those with NF (Figure 3). Mortality was also increased in patients with low EF compared with those with normal EF (allcause mortality HR: 1.75, 95\% CI: 1.31-2.33, p<0.001; cardiovascular mortality HR: 3.09, 95\% CI: $2.01-4.75, \mathrm{p}<0.001)$ and in patients with LG compared with those with HG (all-cause mortality HR: $1.75,95 \%$ CI: 1.30-2.37, $<<0.001$; cardiovascular mortality HR: 2.53, 95\% CI: 1.63-3.94, p<0.001).

Patients in the NF-HG, NF-LG, and LF-HG groups had similar outcomes (all-cause mortality $\mathrm{p}=0.49$; cardiovascular mortality $\mathrm{p}=0.11$ ), whereas all-cause mortality was significantly higher in the LF-LG group compared with the NF-HG (HR: 2.31, 95\% CI: $1.59-3.36, \mathrm{p}<0.001$ ), and the LF-HG (HR: $1.89,95 \% \mathrm{CI}$ : 1.32-2.72, $\mathrm{p}=0.01$ ) groups (Figure 4). All-cause mortality was borderline significantly higher in the LF-LG group compared with the NF-LG group (HR: 1.79, 95\% CI: 0.96-3.31, p=0.066). Cardiovascular mortality was also increased in the LF-LG group compared with the NF-HG (HR: 3.92, 95\% CI: 2.18-7.05, p<0.001) and the LF-HG (HR: 2.40, 95\% CI: 1.42-4.07, p=0.001) groups. After further dichotomisation of the LF-LG group according to LVEF, no significant difference was observed between LF-LGNEF and LF-LG-LEF subgroups with respect to all-cause mortality $(\mathrm{p}=0.16$ ), but there was increased cardiovascular mortality in patients with classical LF-LG-LEF compared to patients with paradoxical LF-LG-NEF ( $\mathrm{p}=0.04$ ) (Figure 5).

Predictors of all-cause mortality are shown in Table 3. Although in a univariable analysis SVi was found to be a significant predictor of both all-cause and cardiovascular mortality, in a multivariable analysis it was not an independent predictor of both all-cause mortality (HR: $1.16,95 \%$ CI: $0.99-1.37$ per $10 \mathrm{ml} / \mathrm{m}^{2}$ decrease, $\mathrm{p}=0.075$ ) and cardiovascular mortality (HR: $1.21,95 \%$ CI: $0.93-1.58$ per $10 \mathrm{ml} / \mathrm{m}^{2}$ decrease, $\left.\mathrm{p}=0.16\right)$. Aortic
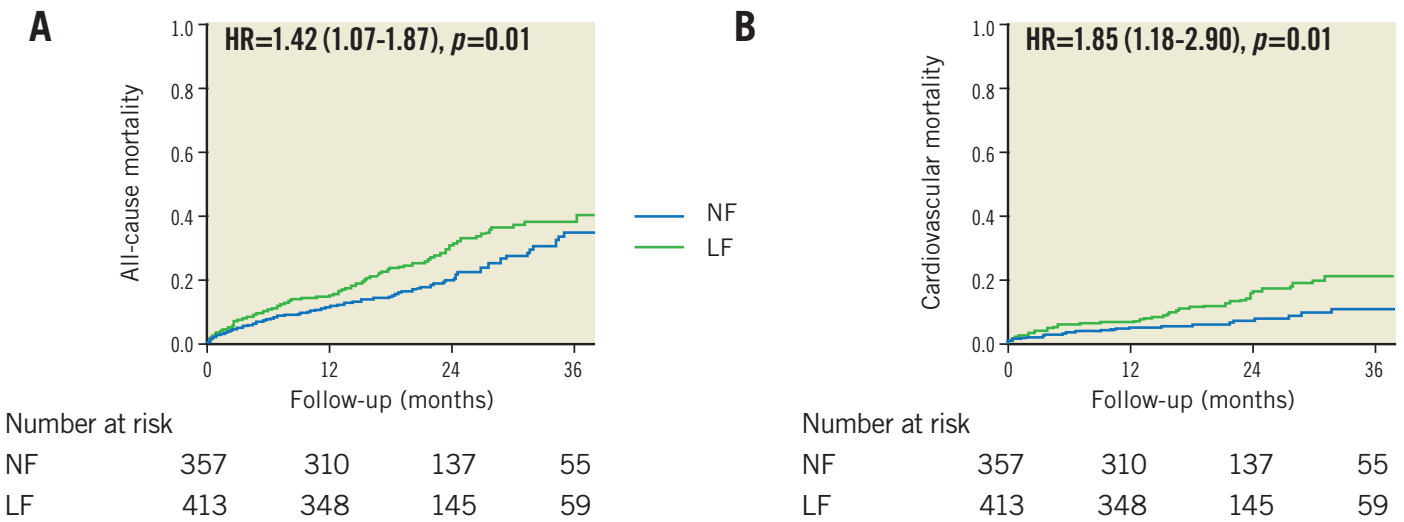

Figure 3. Kaplan-Meier curves following TAVR according to stroke volume indexed to body surface area. Curves for all-cause mortality (A) and cardiovascular mortality (B). LF: low flow; NF: normal flow
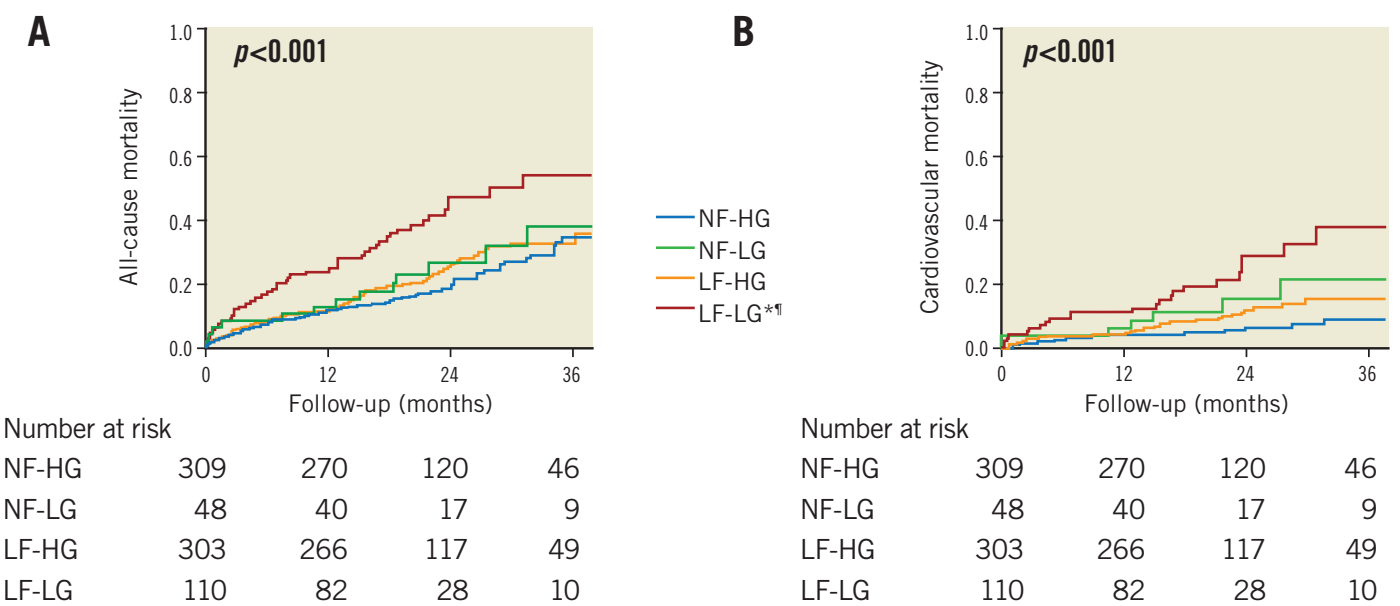

Figure 4. Kaplan-Meier curves for the four groups of patients separated according to flow and gradient levels. Curves for all-cause mortality (A) and cardiovascular mortality (B). * ${ }^{*}<0.05$ vs. NF-HG. " $p<0.05$ vs. LF-HG. LF-HG: low flow and high gradient; LF-LG: low flow, low gradient; $N F-H G$ : normal flow and high gradient; $N F-L G$ : normal flow and low gradient 
A

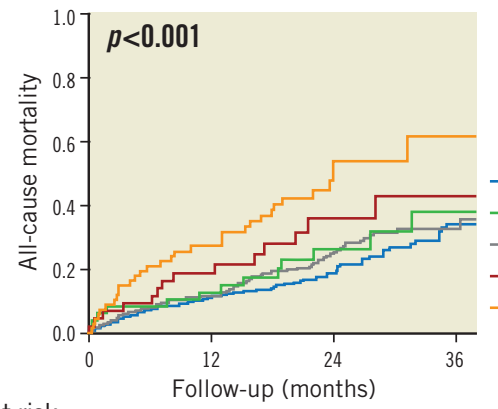

Number at risk

$\begin{array}{lrrrr}\text { NF-HG } & 309 & 270 & 120 & 46 \\ \text { NF-LG } & 48 & 40 & 17 & 9 \\ \text { LF-HG } & 303 & 266 & 117 & 49 \\ \text { LF-LG-NEF } & 43 & 34 & 13 & 5 \\ \text { LF-LG-LEF } & 67 & 48 & 15 & 5\end{array}$

B

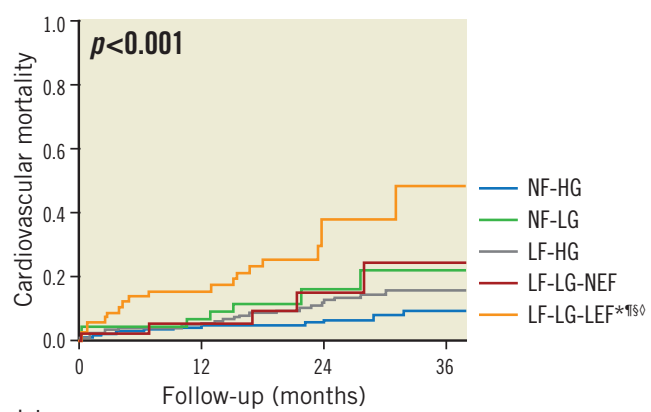

Number at risk

$\begin{array}{lrrrr}\text { NF-HG } & 309 & 270 & 120 & 46 \\ \text { NF-LG } & 48 & 40 & 17 & 9 \\ \text { LF-HG } & 303 & 266 & 117 & 49 \\ \text { LF-LG-NEF } & 43 & 34 & 13 & 5 \\ \text { LF-LG-LEF } & 67 & 48 & 15 & 5\end{array}$

Figure 5. Kaplan-Meier curve analysis after further dichotomisation of the LF-LG group according to left ventricular ejection fraction. Curves for all-cause mortality (A) and cardiovascular mortality (B). ${ }^{*} p<0.05 v s . N F-H G .{ }^{~} p<0.05 v s . L F-H G .{ }^{\S} p<0.05 v s . N F-L G .{ }^{\circledR} p<0.05 v s$. $L F-L G-N E F$. LF-HG: low flow and high gradient; $L F-L G-L E F$ : low flow, low gradient, and low ejection fraction; $L F-L G-N E F$ : low flow, low gradient, and normal ejection fraction; NF-HG: normal flow and high gradient; NF-LG: normal flow and low gradient

Table 3. Multivariate Cox proportional hazard analysis of all-cause mortality.

\begin{tabular}{|c|c|c|c|c|c|c|}
\hline \multirow[b]{2}{*}{ Variable } & \multicolumn{3}{|c|}{ Univariate analysis } & \multicolumn{3}{|c|}{ Multivariate analysis } \\
\hline & Hazard ratio & $\begin{array}{l}\text { Confidence } \\
\text { interval }\end{array}$ & $p$-value & Hazard ratio & $\begin{array}{l}\text { Confidence } \\
\text { interval }\end{array}$ & $p$-value \\
\hline Age (per 1-year increase) & 1.02 & $1.00-1.04$ & 0.03 & 1.00 & $0.98-1.02$ & 0.84 \\
\hline Gender (male) & 1.07 & $0.81-1.42$ & 0.64 & & & \\
\hline Body mass index $\left(\mathrm{kg} / \mathrm{m}^{2}\right)$ & 0.97 & 0.94-0.99 & 0.02 & 0.98 & $0.95-1.01$ & 0.25 \\
\hline Diabetes mellitus & 1.40 & $1.06-1.85$ & 0.02 & 1.37 & $1.01-1.86$ & 0.04 \\
\hline Hypertension & 0.77 & $0.49-1.20$ & 0.24 & & & \\
\hline Coronary artery disease & 0.99 & $0.75-1.31$ & 0.94 & & & \\
\hline Previous myocardial infarction & 1.28 & $0.91-1.80$ & 0.16 & & & \\
\hline Previous CABG & 0.99 & $0.72-1.35$ & 0.93 & & & \\
\hline Peripheral artery disease & 1.20 & $0.91-1.57$ & 0.21 & & & \\
\hline Previous stroke/TIA & 1.17 & $0.85-1.62$ & 0.35 & & & \\
\hline Chronic lung disease & 1.34 & $1.02-1.76$ & 0.04 & 1.28 & $0.94-1.74$ & 0.12 \\
\hline $\begin{array}{l}\text { Chronic renal failure (glomerular filtration rate } \\
<30 \mathrm{~mL} / \mathrm{min} / \mathrm{m}^{2} \text { ) }\end{array}$ & 2.63 & $1.97-3.52$ & $<0.001$ & 1.81 & $1.27-2.59$ & 0.001 \\
\hline Previous pacemaker & 1.36 & $1.00-1.86$ & 0.05 & 0.83 & $0.58-1.18$ & 0.29 \\
\hline Permanent atrial fibrillation/flutter & 1.36 & $1.03-1.79$ & 0.03 & 1.23 & $0.91-1.67$ & 0.18 \\
\hline Society of Thoracic Surgeons score (per $1 \%$ increase) & 1.09 & $1.07-1.12$ & $<0.001$ & 1.06 & 1.03-1.09 & $<0.001$ \\
\hline LVEF (per 10\% decrease) & 1.14 & $1.04-1.24$ & 0.004 & 1.01 & $0.90-1.12$ & 0.92 \\
\hline AV mean gradient (per 10 mmHg decrease) & 1.22 & $1.10-1.35$ & $<0.001$ & 1.14 & $1.02-1.27$ & 0.02 \\
\hline AVA & 0.62 & $0.25-1.54$ & 0.30 & & & \\
\hline Stroke volume index (per $10 \mathrm{ml} / \mathrm{m}^{2}$ decrease) & 1.18 & $1.03-1.36$ & 0.02 & 1.16 & $0.99-1.37$ & 0.075 \\
\hline Moderate-severe AR & 0.97 & $0.61-1.54$ & 0.89 & & & \\
\hline Moderate-severe MR & 1.85 & $1.38-2.47$ & $<0.001$ & 1.39 & $1.00-1.91$ & 0.048 \\
\hline CT mean annulus diameter, $\mathrm{mm}$ & 0.99 & 0.94-1.05 & 0.80 & & & \\
\hline CT AV Agatston calcification score (per $100 \mathrm{AU}$ increase) & 1.00 & $0.99-1.01$ & 0.74 & & & \\
\hline Valve type: SAPIEN 3 vs. others & 0.58 & $0.38-0.97$ & 0.01 & 0.80 & $0.52-1.22$ & 0.30 \\
\hline Alternative access (transapical/transaortic/subclavian) & 2.04 & $1.46-2.84$ & $<0.001$ & 1.84 & $1.29-2.64$ & 0.001 \\
\hline
\end{tabular}


valve mean gradient was an independent predictor of both allcause mortality (HR: $1.14,95 \% \mathrm{CI}: 1.02$ to 1.27 per $10 \mathrm{mmHg}$ decrease, $\mathrm{p}=0.02$ ) and cardiovascular mortality (HR: $1.29,95 \%$ CI: 1.07 to 1.54 per $10 \mathrm{mmHg}$ decrease, $\mathrm{p}=0.001$ ) in multivariable analyses. Although it was a significant mortality predictor in univariable analysis, LVEF was not an independent predictor in multivariable analysis (Table 3 ). In a similar ancillary multivariable analysis including the five different flow/gradient/EF groups, only LF-LG-LEF was independently significantly associated with increased overall mortality compared to NF-HG (HR: 2.08, 95\% CI: 1.32-3.27, p=0.002). LF-LG-NEF was associated with a trend for increased mortality in this model (HR: 1.69, 95\% CI: 0.94-3.02, $\mathrm{p}=0.077$ ).

\section{Discussion}

The major findings of this study are as follows. 1) More than half of the patients who had TAVR were in an LF state and about $20 \%$ had LG prior to the procedure. 2) Univariable analysis found LF, LEF and LG to be predictors of overall and cardiovascular mortality, but in a multivariable model only LG remained an independent predictor of mortality. 3) Patients with LF-LG had increased mortality following TAVR compared with those with NF-HG, NF-LG, and LF-HG. 4) Among patients with LF-LG, those with LEF (classical LF-LG) had increased cardiovascular mortality compared to those with NEF (paradoxical LF-LG AS).

Standard parameters of AS severity, including AVA and transvalvular gradients, vary with flow ${ }^{16}$. Patients with AS are subdivided by these parameters combined with their LVEF. These subgroups were found to have different outcomes in the natural course of the dis-

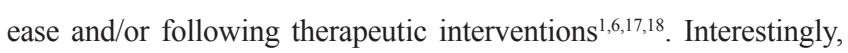
most of the studies that have examined directly the effect of LVEF or transvalvular gradients on the outcome following TAVR did not include stroke volume in their analysis ${ }^{9-11}$. Two previous studies analysed the impact of LF, LG and LEF on mortality following TAVR $^{12,13}$. Both of these studies reported that LF and LG are significantly associated with mortality in a univariable analysis, but only reduced SVi remained statistically significant in a multivariable model. The results of the present study are different from these two studies. In the present analysis, LG was found to be an independent predictor of overall and cardiovascular mortality but LF and LEF only predicted mortality in a univariable model.

A possible explanation for the discrepancies in the results of the present study and the previous two studies presented above may derive from a different time period in which TAVR was performed. While the previous studies reported outcome of patients who underwent TAVR between 2005 and the beginning of $2012^{12,13}$, all patients in the present study underwent TAVR between 2012 and 2014. Advances in technology providing new generations of devices with reduced profile sizes and improved navigability, utilisation of CT for better annular sizing and increased operator and anaesthesiologist experience have reduced short-term mortality dramatically. While Le Ven et a ${ }^{12}$ reported increased 30-day mortality in patients with LF vs. NF (11.4 vs. $5.9 \%, \mathrm{p}=0.01)$, we found a substantially lower 30-day mortality, similar between LF and NF patients $(3.6 \%$ and $2.8 \%$, respectively, $\mathrm{p}=0.52)$. This low mortality rate is compatible with recent contemporary short-term mortality reports ${ }^{19}$. With the marked reduction in overall periprocedural mortality and morbidity with TAVR during the past 10 years, the association between LF and mortality, and especially short-term mortality, may have become less important in the most recent series, including the present one.

\section{Study limitations}

The main limitation of the present study is that it represents a retrospective, single-centre experience. We analysed stroke volume using the Doppler-derived two-dimensional LVOT diameter and VTI without confirmation of invasive haemodynamic measurements. The definition of LF is not standardised in the literature, but we chose a definition $\left(\mathrm{SVi} \leq 35 \mathrm{~mL} / \mathrm{m}^{2}\right.$ ) that has been commonly used $^{1,10,12,13}$. Moreover, patients with LF had more comorbidities and higher STS scores at baseline which, despite multivariable analysis, may have biased the results. Future studies with a larger number of patients, longer follow-up and the use of different valve types may further clarify this subject.

\section{Conclusions}

LF is a common finding in patients with severe AS. Patients with NF-LG have excellent outcomes following TAVR, something which is similar to those of patients with HG AS, whereas those with LF-LG AS have an increased risk of mortality. Among patients with LF-LG, those with LEF (classical LF-LG) have increased mortality compared to those with NEF (paradoxical LF-LG AS). In contrast to previous reports, LG but not LF or LEF is an independent predictor of late mortality in high-risk patients with severe AS undergoing TAVR.

\section{Impact on daily practice}

Patients with NF-LG have excellent outcomes following TAVR, similar to those of patients with HG AS, whereas those with LF-LG AS have an increased risk of mortality. In contrast to previous reports, the present study demonstrated that $\mathrm{LG}$, but not LF or LEF, is an independent predictor of late mortality following TAVR. Future studies should evaluate whether earlier intervention is indicated to reduce the adverse effects of LG and/or LF.

\section{Funding}

The study was funded by internal departmental resources.

\section{Conflict of interest statement}

R. Makkar has received grant support from Edwards Lifesciences and St. Jude Medical and is a consultant for Abbott Vascular, Cordis, and Medtronic. P. Pibarot has received a research grant from Edwards Lifesciences for echocardiography core lab analyses. The other authors have no conflicts of interest to declare. 


\section{References}

1. Pibarot P, Dumesnil JG. Low-flow, low-gradient aortic stenosis with normal and depressed left ventricular ejection fraction. J Am Coll Cardiol. 2012;60:1845-53.

2. Connolly HM, Oh JK, Orszulak TA, Osborn SL, Roger VL, Hodge DO, Bailey KR, Seward JB, Tajik AJ. Aortic valve replacement for aortic stenosis with severe left ventricular dysfunction. Prognostic indicators. Circulation. 1997;95:2395-400.

3. Levy F, Laurent M, Monin JL, Maillet JM, Pasquet A, Le Tourneau T, Petit-Eisenmann H, Gori M, Jobic Y, Bauer F, Chauvel C, Leguerrier A, Tribouilloy C. Aortic valve replacement for low-flow/low-gradient aortic stenosis operative risk stratification and long-term outcome: a European multicenter study. J Am Coll Cardiol. 2008;51:1466-72.

4. Parikh R, Goodman AL, Barr T, Sabik JF, Svensson LG, Rodriguez LL, Lytle BW, Grimm RA, Griffin BP, Desai MY. Outcomes of surgical aortic valve replacement for severe aortic stenosis: Incorporation of left ventricular systolic function and stroke volume index. J Thorac Cardiovasc Surg. 2015;149:1558-66.

5. Nishimura RA, Otto CM, Bonow RO, Carabello BA, Erwin JP 3rd, Guyton RA, O'Gara PT, Ruiz CE, Skubas NJ, Sorajja P, Sundt TM 3rd, Thomas JD; American College of Cardiology/ American Heart Association Task Force on Practice Guidelines. 2014 AHA/ACC guideline for the management of patients with valvular heart disease: executive summary: a report of the American College of Cardiology/American Heart Association Task Force on Practice Guidelines. J Am Coll Cardiol. 2014;63:2438-88.

6. Dayan V, Vignolo G, Magne J, Clavel MA, Mohty D, Pibarot P. Outcome and Impact of Aortic Valve Replacement in Patients With Preserved LVEF and Low-Gradient Aortic Stenosis. J Am Coll Cardiol. 2015;66:2594-603.

7. Makkar RR, Fontana GP, Jilaihawi H, Kapadia S, Pichard AD, Douglas PS, Thourani VH, Babaliaros VC, Webb JG, Herrmann HC, Bavaria JE, Kodali S, Brown DL, Bowers B, Dewey TM, Svensson LG, Tuzcu M, Moses JW, Williams MR, Siegel RJ, Akin JJ, Anderson WN, Pocock S, Smith CR, Leon MB; PARTNER Trial Investigators. Transcatheter aortic-valve replacement for inoperable severe aortic stenosis. N Engl J Med. 2012;366:1696-704.

8. Kodali SK, Williams MR, Smith CR, Svensson LG, Webb JG, Makkar RR, Fontana GP, Dewey TM, Thourani VH, Pichard AD, Fischbein M, Szeto WY, Lim S, Greason KL, Teirstein PS, Malaisrie SC, Douglas PS, Hahn RT, Whisenant B, Zajarias A, Wang D, Akin JJ, Anderson WN, Leon MB; PARTNER Trial Investigators. Two-year outcomes after transcatheter or surgical aortic-valve replacement. $N$ Engl J Med. 2012;366:1686-95.

9. Sannino A, Gargiulo G, Schiattarella GG, Brevetti L, Perrino C, Stabile E, Losi MA, Toscano E, Giugliano G, Scudiero F, Chiacchio E, Trimarco B, Esposito G. Increased mortality after transcatheter aortic valve implantation (TAVI) in patients with severe aortic stenosis and low ejection fraction: a meta-analysis of 6898 patients. Int J Cardiol. 2014;176:32-9.
10. Eleid MF, Goel K, Murad MH, Erwin PJ, Suri RM, Greason KL, Nishimura RA, Rihal CS, Holmes DR Jr. MetaAnalysis of the Prognostic Impact of Stroke Volume, Gradient, and Ejection Fraction After Transcatheter Aortic Valve Implantation. Am J Cardiol. 2015;116:989-94.

11. Amabile N, Agostini H, Gilard M, Eltchaninoff H, Iung B, Donzeau-Gouge P, Chevreul K, Fajadet J, Leprince P, Leguerrier A, Lievre M, Prat A, Teiger E, Laskar M, Caussin C. Impact of low preprocedural transvalvular gradient on cardiovascular mortality following TAVI: an analysis from the FRANCE 2 registry. EuroIntervention. 2014;10:842-9.

12. Le Ven F, Freeman M, Webb J, Clavel MA, Wheeler M, Dumont É, Thompson C, De Larochellière R, Moss R, Doyle D, Ribeiro HB, Urena M, Nombela-Franco L, Rodés-Cabau J, Pibarot P. Impact of low flow on the outcome of high-risk patients undergoing transcatheter aortic valve replacement. $\mathrm{J} \mathrm{Am} \mathrm{Coll}$ Cardiol. 2013;62:782-8.

13. Herrmann HC, Pibarot P, Hueter I, Gertz ZM, Stewart WJ, Kapadia S, Tuzcu EM, Babaliaros V, Thourani V, Szeto WY, Bavaria JE, Kodali S, Hahn RT, Williams M, Miller DC, Douglas PS, Leon MB. Predictors of mortality and outcomes of therapy in lowflow severe aortic stenosis: a Placement of Aortic Transcatheter Valves (PARTNER) trial analysis. Circulation. 2013;127:2316-26.

14. Agatston AS, Janowitz WR, Hildner FJ, Zusmer NR, Viamonte M Jr, Detrano R. Quantification of coronary artery calcium using ultrafast computed tomography. $\mathrm{J} \mathrm{Am} \mathrm{Coll} \mathrm{Cardiol.}$ 1990; $15: 827-32$.

15. Kappetein AP, Head SJ, Généreux P, Piazza N, van Mieghem NM, Blackstone EH, Brott TG, Cohen DJ, Cutlip DE, van Es GA, Hahn RT, Kirtane AJ, Krucoff MW, Kodali S, Mack MJ, Mehran R, Rodés-Cabau J, Vranckx P, Webb JG, Windecker S, Serruys PW, Leon MB. Updated standardized endpoint definitions for transcatheter aortic valve implantation: the Valve Academic Research Consortium-2 consensus document. J Am Coll Cardiol. 2012;60:1438-54.

16. Burwash IG, Thomas DD, Sadahiro M, Pearlman AS, Verrier ED, Thomas R, Kraft CD, Otto CM. Dependence of Gorlin formula and continuity equation valve areas on transvalvular volume flow rate in valvular aortic stenosis. Circulation. 1994;89:827-35.

17. Hachicha Z, Dumesnil JG, Bogaty P, Pibarot P. Paradoxical low-flow, low-gradient severe aortic stenosis despite preserved ejection fraction is associated with higher afterload and reduced survival. Circulation. 2007;115:2856-64.

18. Clavel MA, Dumesnil JG, Capoulade R, Mathieu P, Sénéchal M, Pibarot P. Outcome of patients with aortic stenosis, small valve area, and low-flow, low-gradient despite preserved left ventricular ejection fraction. J Am Coll Cardiol. 2012;60:1259-67.

19. Webb J, Gerosa G, Lefèvre T, Leipsic J, Spence M, Thomas M, Thielmann M, Treede H, Wendler O, Walther T. Multicenter evaluation of a next-generation balloon-expandable transcatheter aortic valve. J Am Coll Cardiol. 2014;64:2235-43. 